\title{
Electrochemical biosensor based on biomimetic material for myoglobin detection
}

\author{
Felismina T.C. Moreira, Rosa A.F. Dutra, João P.C. Noronha, M. Goreti F. Sales
}

\section{A B S T R A C T}

A novel reusable molecularly imprinted polymer (MIP) assembled on a polymeric layer of carboxylated poly(vinyl chloride)(PVC $\mathrm{COOH}$ ) for myoglobin (Myo) detection was developed. This polymer was casted on the gold working area of a screen printed electrode (Au-SPE), creating a novel disposable device relying on plastic antibodies. Electrochemical impedance spectroscopy (EIS), cyclic voltammetry (CV) and Fourier transform infrared spectroscopy (FTIR) studies confirmed the surface modification.

The MIP/Au-SPE devices displayed a linear behaviour in EIS from 0.852 to $4.26 \mu \mathrm{g} \mathrm{mL}^{-1}$, of positive slope $6.50 \pm 1.48\left(\mathrm{k} \Omega \mathrm{mL}_{\mu \mathrm{g}}{ }^{-1}\right)$. The limit of detection was $2.25 \mu \mathrm{g} \mathrm{mL}^{-1}$. Square wave voltammetric (SWV) assays were made in parallel and showed linear responses between 1.1 and $2.98 \mu \mathrm{g} \mathrm{mL}^{-1}$. A current decrease was observed against Myo concentration, producing average slopes of $-0.28 \pm 0.038 \mu \mathrm{AmL} \mu \mathrm{g}^{-1}$. MIP/Au-SPE also showed good results in terms of selectivity. The error\% found for each interfering species were $7 \%$ for troponin T (TnT), $11 \%$ for bovine serum albumin (BSA) and $2 \%$ for creatine kinase MB (CKMB), respectively. Overall, the technical modification over the Au-SPE was found a suitable approach for screening Myo in biological fluids.

Keywords:

Biosensor

Surface molecular imprint

Screen printed electrodes

Sensor

Myoglobin

\section{Introduction}

The selective detection/quantification of proteins, as biomarkers of diseases, environmental monitoring, and food control has been a subject of great interest in the last decade [1]. Biosensors are emerged in this context as primary tools. They offer many advantages such as low cost, versatility, good sensitivity, selectivity, and reliability $[2,3]$. Biosensors based on screen-printed electrodes (SPE) are especially attractive for point-of-care/on-site monitoring because of their small-size and portability. The easy of production and low-cost materials involved in the screen-printing technology have lead to the massive production of such devices [4]. SPEs are also disposable devices, which is an important feature for clinical applications.

In general, biosensors are capable of transforming their interaction with specific analytes into an electronic signal. At the core of this feature is a biorecognition element that is expected to establish exceptionally selective interactions with a target analyte.
Biorecognition elements include a wide range of macromolecules, such as enzymes, receptors, ion channel proteins, nucleic acids, aptamers, peptides or antibodies. These were first from natural origin but the advances of nanotechnology have come up with many synthetic versions of these elements [5-7].

The great selectivity of the antibodies has always been a great advantage for biosensors $[8,10,11]$, a feature that justifies that most biosensors described in the literature for Myo detection were immunosensing devices $[8,9]$. All these display good features in terms of linear range and selectivity. However, natural antibodies are also very expensive material, usually produced by an animal dependent process, and unable to be reused after their first contact with the target template.

Thus, the great cost of these biorecognition elements in parallel to their small stability, has led researchers to the design new materials capable of mimicking the response of antibodies. This has been tried out for several decades, with the most successful approaches using molecular imprint technology [12,7,13].

This is a low-cost and simple approach for designing selective binding sites in polymeric matrices using the target molecule as template. This technology offers great promise for the development of stable artificial bio-sensing elements [14].

Several techniques have been employed in molecular imprinting, differing mainly from the type of interaction between the 
functional monomer and the template prior to polymerization. This may be covalent, non-covalent or semi-covalent nature [15]. Noncovalent imprinting is by far the most popular strategy [16] due to the easy preparation and the wide range of monomers available for this process. The template may also be introduced in the system differently: it may stand free or be attached to a surface, thus creating, respectively, 3D or 2D imprinting environments. The former one is also called surface imprinting and seems to improve protein binding kinetics [17], overcoming some difficulties to mass transfer and protein removal in imprinted matrices [13].

Thus, combining surface imprinting with SPE technology seems an advantageous approach to create new disposable and low cost biomedical devices. This concept has been applied here by assembling the MIP directly on the SPE working area, having Myo as target protein. Myo can be detected in biological fluids such as serum and urine. Myo cut-off values in serum range from 100 to $200 \mathrm{ng} \mathrm{mL}^{-1}$ $[9,18,19]$. In acute myocardial infarction (AMI) condition, Myo maximum levels are variable; concentrations of $420-600 \mathrm{ng} \mathrm{mL}^{-1}$ have been found in previous studies [18]. After $4-50 \mathrm{~h}$ of an AMI episode, Myo is also expected in urine [20]. These levels are also rather variable and may reach $450 \mathrm{mg} \mathrm{mL}^{-1}$ [20,21].

So far, different strategies for Myo detection and quantification based on surface imprinting were described in the literature, including sol-gel methods merged with self assembling monolayer for potentiometric transduction [6,22], silicon surface grafting [13] and thin film/micro contact imprinting mass with spectrometrybased profiling system [23], none of these coupling these two simple concepts of MIP receptors and SPE technology.

Several techniques have been described in the literature for Myo quantification [24-28]. Electro-analytical techniques [9,19,29-33] have concerned considerable attention due to its sensitive, nondestructive, and rapid electrochemical sensing method.

This research paper describes a new disposable biomedical device for monitoring Myo in point-of-care, designed by coating the conductive working area of a SPE with a PVC-COOH film and assembling the MIP on top of it. For this purpose, Myo was bound to the $-\mathrm{COOH}$ groups after their activation and the MIP designed by a polymeric matrix, amide in nature. This matrix had non-charged amide groups, polymerized in aqueous environment and was biocompatible to protein targets. Finally, the template was removed by chemical treatment as suggested in [34]. The several steps of surface modification and the analytical performance of the resulting device were controlled by electrochemical techniques and FTIR studies. The MIP/Au-SPE characteristic towards the quantitative estimation of the Myo concentration was investigated by EIS and SWV, $\left[\mathrm{Fe}(\mathrm{CN})_{6}\right]^{3-} /^{4-}$ was used as a redox probe. The biosensor showed good electrochemical features in terms of response time, sensitivity and selectivity. This biodevice shows to be a powerful tool for screening Myo in patients with ischaemic episodes.

\section{Experimental}

\subsection{Apparatus}

The electrochemical measurements were carried out using a Metrohm-autolab potentiostat/galvanostat Autolab PGSTAT302N interfaced to computer. The SPEs were purchased from Dropsens, Spain (DRP-C220AT), and had a working gold electrode of $4 \mathrm{~mm}$ and a silver flat material acting as pseudoreference. Infrared spectra were collected by a Nicolet 670 Fourier transform infrared spectroscopy (FTIR) spectrometer. Measurements were conducted in ATR (Attenuated Total Reflectance) mode by a Nicolet ATR sampling accessory of diamond contact crystal. When necessary, the $\mathrm{pH}$ was measured by a Crison CWL/S7 combined glass electrode connected to a decimilivoltammeter Crison, pH metre, GLP 22.

\subsection{Reagents}

All chemicals were of analytical grade and de-ionized water (conductivity $<0.1 \mu \mathrm{S} \mathrm{cm}^{-1}$ ) was employed. The following reagents were employed: Myo from cardiac muscle (Fluka); PVC-COOH (Fluka); 4-(2-hydroxyethyl)-1piperazineethanesulfonic acid (HEPES, Fluka); 1-ethyl-3-(3dimethylaminopropyl)carbodiimide (EDAC, Fluka); oxalic acid (Oac, Fluka); $N, N$-methylenebisacrylamide (NNMBA, Fluka); albumin, bovine serum (BSA, Fluka); creatine kinase MB (CKMB, Fluka); ammonium persulphate (APS, Fluka); potassium chloride $(\mathrm{KCl}$ Panreac); (hydroxymethyl)aminomethane (Tris, Panreac); potassium dihydrogen phosphate $\left(\mathrm{KH}_{2} \mathrm{PO}_{4}\right.$, Penreac); acrylamide (AAM, Fisher Bioreagents); N-hydroxysuccinimide (NHS, Acros); tetrahydrofuran (THF, Riedel-deHäen); potassium hexacyanoferrate (III) $\left(\left[\mathrm{Fe}(\mathrm{CN})_{6}\right]^{3-}\right.$; Riedel-deHäen); sodium chloride ( $\mathrm{NaCl}$, RiedeldeHäen); sodium phosphate dibasic dehydrate $\left(\mathrm{Na}_{2} \mathrm{HPO}_{4} \cdot 2 \mathrm{H}_{2} \mathrm{O}\right.$, Riedel-deHäen); potassium hexacyanoferrate (II) $\left(\left[\mathrm{Fe}(\mathrm{CN})_{6}\right]^{4-}\right.$ ) trihydrate (Riedel-deHäen); and sodium hydrogen phosphate $\left(\mathrm{Na}_{2} \mathrm{HPO}_{4}\right)$ dihydrate (Riedel-deHäen).

\subsection{Solutions}

Buffer solutions were $1.0 \times 10^{-1} \mathrm{~mol} \mathrm{dm}^{-3} \quad$ PBS, $1.0 \times 10^{-1} \mathrm{~mol} \mathrm{dm}^{-3}$ Tris or $1.0 \times 10^{-2} \mathrm{~mol} \mathrm{dm}^{-3}$ HEPES. The $\mathrm{pH}$ of the buffer solution was adjusted to the desired value by adding suitable volumes of either concentrated hydrochloric acid or saturated sodium hydroxide solution freshly prepared.

Stock standard solutions of Myo were $5.0 \times 10^{-7} \mathrm{~mol} \mathrm{dm}^{-3}$ and prepared in buffer. Less concentrated solutions were prepared by accurate dilution of the previous solution in the same buffer.

\subsection{Synthesis of biomimetic materials}

The working area of the SPE (gold) was cleaned by washing three times with ethanol. The PVC- $\mathrm{COOH}$ layer was obtained by casting on the about $5 \mu \mathrm{dm}^{-3}$ of a solution of $0.021 \mathrm{~g}$ of PVC $-\mathrm{COOH}$ dissolved in $2.5 \mathrm{ml}$ THF. The complete dissolution of the polymer was achieved by magnetic stirring inside a fume hood. About $5 \mu \mathrm{dm}^{-3}$ of this solution was casted. This solution was let dry for $4 \mathrm{~h}$, at room temperature. To activate the $-\mathrm{COOH}$ groups, the dry polymer layer was incubated for $3 \mathrm{~h}$ in an aqueous solution of $50 \mathrm{mmol} \mathrm{dm}^{-3}$ EDAC and $25 \mathrm{~mol} \mathrm{dm}^{-3}$ NHS. The electrode was then rinsed thoroughly with distilled water to remove un-reacted species.

The imprinting stage started by incubating the activated polymer layer in $5 \times 10^{-6} \mathrm{~mol} \mathrm{dm}^{-3}$ Myo solution, prepared in $0.1 \mathrm{~mol} \mathrm{dm}^{-3}$ PBS buffer of $\mathrm{pH}$ 7.4. The incubation time was set to $4 \mathrm{~h}$, at $4{ }^{\circ} \mathrm{C}$. After, the electrode was washed twice with PBS buffer ( $\mathrm{pH}$ 7.4) to remove any exceeding Myo that remained unbound. The sensor was then incubated in $0.5 \mathrm{~mol} \mathrm{dm} \mathrm{m}^{-3}$ Tris for $30 \mathrm{~min}$, in order to block any activated group left over in the surface. Several washes with deionised water followed this procedure. The polymerization stage started by adding $1 \mathrm{ml}$ of a solution containing $1 \mathrm{~mol} \mathrm{dm}^{-3}$

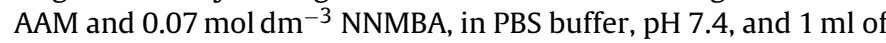
$0.06 \mathrm{~mol} \mathrm{dm}^{-3}$ APS solution, in the same buffer. This polymerization was carried out at room temperature for $5 \mathrm{~h}$, after which the sensor was thoroughly washed with deionised water several times.

The sites displaying complementary features to Myo were obtained by extracting the template from the polymer. Strong acids have the ability to break the protein covalent bonds. For this purpose, $0.5 \mathrm{~mol} \mathrm{dm}^{-3}$ solution of Oac was added to the sensory surface. This was done at room temperature, for $3 \mathrm{~h}$. The MIP was finally washed and conditioned in phosphate buffer, $\mathrm{pH} 7.4$, in order to increase the $\mathrm{pH}$ and remove the peptide fractions produced by Oac treatment. The MIP-SPE was ready to use after washing thoroughly with water. 


\subsection{Infrared surface analysis}

FTIR analysis was conducted in a Nicolet 6700 FTIR spectrometer. Infrared spectra were collected under room temperature/humidity control after background correction. The number of scans was 32 for both sample and background. $X$-axis was wavenumber, ranging $600-4000 \mathrm{~cm}^{-1}$, and $Y$-axis was transmittance $(t, \%)$. Resolution was 4000 .

\subsection{Electrochemical measurements}

$\mathrm{CV}$ and SWV measurements were performed in a solution of $5.0 \mathrm{~mol} \mathrm{dm}^{-3}[\mathrm{Fe}(\mathrm{CN}) 6]^{3-}, 5.0 \mathrm{~mol} \mathrm{dm}^{-3}[\mathrm{Fe}(\mathrm{CN}) 6]^{4-}$, prepared in HEPES buffer and with $\mathrm{pH}$ 5. The selection of this buffer accounts previous studies [6]. The potential was scanned between -0.2 and $+0.4 \mathrm{~V}$, at $30 \mathrm{mV} \mathrm{s}^{-1}$.

EIS analysis was conducted on the SPE-MIP electrodes. Impedance readings were performed in the same solution as indicated for CV and SWV, under a standard potential of $0.225 \mathrm{~V}$, a number of frequencies equal to 50 and amplitude of $0.01 \mathrm{~V}$. The frequency range was $0.1-100 \mathrm{kHz}$. The impedance data were fitted to a Randles equivalent circuit using the implemented ANOVA software.

\subsection{Selectivity study}

Selectivity studies were conducted by competitive assay between Myo, with a $4.0 \mu \mathrm{g} \mathrm{mL}^{-1}$ concentration, and TnT (0.22 $\left.\mathrm{ng} \mathrm{mL}^{-1}\right)$, BSA ( $\left.1 \mathrm{mg} \mathrm{mL}^{-1}\right)$ and CKMB ( $\left.5 \mathrm{ng} \mathrm{mL}^{-1}\right)$ solutions. All these were prepared in HEPES buffer $\mathrm{pH}$ 5. These concentration values have been selected according to their relative concentration to Myo in biological fluids.

\subsection{Serum samples analysis}

The performance of the sensor was carried out using synthetic serum samples spiked with Myo. The serum was 1:10 diluted in MES buffer and SWV measurements were performed. All assays were performed 3 repeated measurements.

\section{Results and discussion}

\subsection{Chemical assembly of the molecularly imprinted material}

The MIP was assembled on a polymeric film (Fig. 1). This was the most simple and cheap way of binding the protein to a sensory material enabling a signal transduction. PVC- $\mathrm{COOH}$ was selected for this purpose because carboxylic groups enable the covalent binding of proteins under mild conditions after carboxylic activation via carbodiimide chemistry. Furthermore, it is a readily available and cheap material. The polymer film was obtained by dissolving the solid polymer in THF and casting $15 \mu \mathrm{L}$ of this solution over the working electrode of a commercial SPE. This electrode was made of gold, although any other conductive material would suite this purpose.

Carboxylic acid groups were activated by EDAC, forming a highly reactive $\mathrm{O}$-acylisourea intermediate that follows immediate reaction with NHS. The obtained product undergoes easy nucleophilic substitution by any amine group in the outer surface of Myo, resulting in the formation of an amide function binding Myo to the polymer film. The protein molecules remaining in the surface by electrostatic interaction were removed by thorough washing with PBS, pH 7. Any carboxylic acid function remaining active was subsequently inactivated by reaction with Tris.

The binding sites were designed by filling the vacant space around the protein with a suitable polymer. A careful choice of monomers is crucial for a successful imprinting. In general, any protein has a complex structure and many potential recognition sites at their surface, with hydrophobic/hydrophilic regions. Charged sites, hydrogen bonding and hydrophobic interactions are all possible in a single protein. Furthermore, the great flexibility of the protein structure means that it should be polymerized under almost-native conditions so that its shape would be preserved and the binding site accurately designed. Acrylamide matrices meet these criteria [35-38]. They polymerize under mild conditions and carry uncharged functions that establish hydrogen bonds and dipole-dipole interactions with Myo [6].

AAM monomers were selected for this purpose. These monomers were let interact with the protein prior to polymerization. This procedure allowed the orientation of the amide groups towards the sites of the protein with which they would interact more favourably, thus allowing subsequent oriented binding after template removal. A cross-linker of the same chemical nature (NNMBA) was also used in order to create a highly reticulated matrix. This would reduce the flexibility of the polymer and preserve the protein site (as seen in Fig. 1). APS was added to start the polymerization and the monomers were let react for $5 \mathrm{~h}$.

The binding site (MIP, Fig. 1) was obtained after removing the protein from the imprinted cavity. At this stage, the polymer was a rigid and stable structure, for which the protein could be extracted by more or less aggressive treatments. Many approaches may be followed in the literature for this purpose. In this work, extraction was succeeded by incubation in oxalic acid, for $3 \mathrm{~h}[6,34]$. After the sensor was washed with PBS buffer, $\mathrm{pH} 7.4$, a condition ensured a

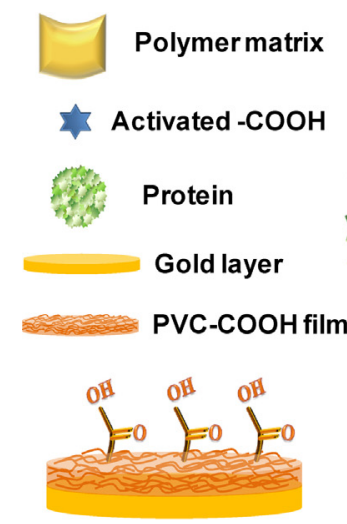

(A)

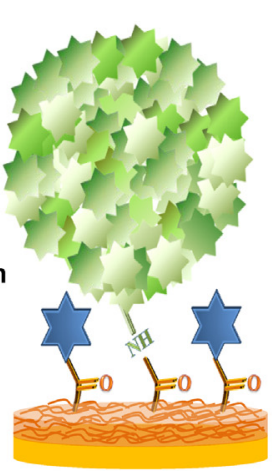

(B)

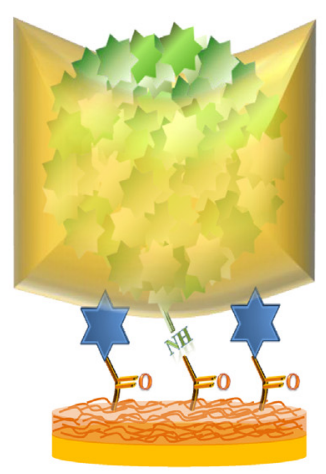

(C)

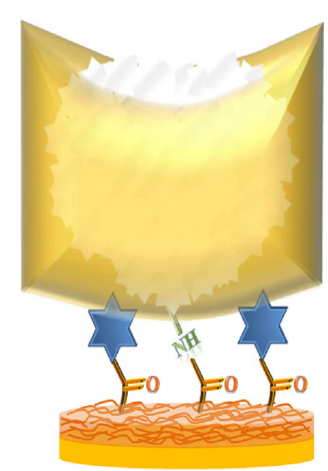

(D)

Fig. 1. Molecular imprinting polymer synthesis. 
more efficient removal of oligopeptides and free amino acids. After thorough washing with water, the material was ready for rebinding with Myo. As control, a similar procedure was made without a template, thus creating a non-imprinted material (NIM).

\subsection{Control of the surface modification}

All modification steps in the preparation of the MIP were followed by FTIR analysis. EIS and CV studies were also used in parallel as they allow investigating the integrity and proprieties of immobilized organic films on the polymer surface and interfacing surface.

\subsubsection{Infrared surface analysis}

The FTIR spectra were taken at all stages of surface modification. This included measuring the typical absorption profile of the PVC- $\mathrm{COOH}$ (A) film casted the gold surface, the subsequent modification with Myo (B) and finally MIP (C) itself. The typical spectra collected for each may be seen in Fig. 2 . The spectrum of gold was not included here because it does not provide relevant information and it is only used as support of the polymer film. The spectrum of Myo was also evaluated because it provides significant insight into the presence of Myo in the polymer.

The presence of carbonyl groups $(\mathrm{C}=\mathrm{O})$ in $\mathrm{PVC}-\mathrm{COOH}$ was evidenced by a strong absorption peak at $1727.8 \mathrm{~cm}^{-1}$. The $\mathrm{C}-\mathrm{H}$ stretch coming from methylene $\left(-\mathrm{CH}_{2}-\right)$ groups in the central carbon chain was evident at $2918.9 \mathrm{~cm}^{-1}$. The rocking absorption from having more than four methylenes in a row was also marked at about $720 \mathrm{~cm}^{-1}$.

The most evident absorption bands in Myo (B) were at 3284.2, 1538.2 and $1651.4 \mathrm{~cm}^{-1}$. These could be correlated to the many functional groups among the side chains of each amino acid. Considering the wave number at which these occur, it is quite probable that they come from alcohol, amine and/or amide groups in the protein. The band at $1398 \mathrm{~cm}^{-1}$ correlates well with the hydroxyl $(-\mathrm{OH})$ function and that at $1062 \mathrm{~cm}^{-1}$ with the $\mathrm{C}-\mathrm{N}$ stretching.

The presence of protein species attached to the polymeric film was quite evident by combining the spectra of PVC-COOH and Myo (C). Almost all bands belonged to PVC- $\mathrm{COOH}$, with the exception of the three most significant bands from Myo. The large band centred at $3342 \mathrm{~cm}^{-1}$ suggested the presence of amide groups from the protein $\left(-\mathrm{CONH}_{2}-\right)$. The two bands at about 1540 and $1650 \mathrm{~cm}^{-1}$ were also from Myo but of less intensity, a consequence of being in lower concentration than in the pure solid.

The polymerization step (D) imputed slight alterations in the FTIR profile of the material. These alterations were not significant because only amide functions were introduced, both by monomer and cross-linker structures, and they were already there, coming from the protein. Overall, the biomaterial displayed an absorption band near $3294 \mathrm{~cm}^{-1}$ that was assigned to $\mathrm{N}-\mathrm{H}$ stretching vibration. The $\mathrm{C}-\mathrm{N}$ stretching vibrations could also be observed at $1000 \mathrm{~cm}^{-1}$. Still, as the protein had been removed from the polymeric structure, it is quite likely that these typical bands of the amide groups were not from the same source as previously.

\subsubsection{Electrochemical impedance spectroscopy}

The organic modification of a gold SPE surface is expected to change the electrical output of the solid-state probe. These changes can be observed by monitoring the alterations in the electrical transfer of a well known redox system, such as $\left[\mathrm{Fe}(\mathrm{CN})_{6}\right]^{4-} /\left[\mathrm{Fe}(\mathrm{CN})_{6}\right]^{3-}$. Several electrochemical approaches may be used for this purpose, being EIS one of the most sensitive.

EIS evaluates the changes in resistance of the polymer surface along each modification step. The Randle's equivalent circuit was adopted to model the process in the gold surface. This circuit was composed by the resistance of the solution phase $\left(R_{\mathrm{S}}\right)$, the capacitance of the double layer $\left(C_{\mathrm{dll}}\right)$, the charge-transfer resistance $\left(R_{\mathrm{ct}}\right)$ and the Warburg diffusion element $(W)$ from the bulk solution to the electrode interface. Typical plots may include a semicircle region lying on the real axis followed by a straight line. The semicircle is observed at high frequency range and implies a charge-transfer controlled process. The diameter of this semicircle equals the $R_{\mathrm{ct}}$, and this resistance controls the electron transfer kinetics of the redox probe at the electrode interface [39].

The EIS spectra by this Randle's equivalent circuit were recorded for every step of the gold SPE surface modification and the results were presented as Nyquist plots (Fig. 3A). The gold SPE coated with a PVC-COOH membrane displayed high electron transfer resistance due the PVC-COOH layer casted on the gold. This behaviour was already expected, owing the absence/weak electrostatic interactions between the uncharged carboxylic acid groups $(-\mathrm{COOH})$ of the polymeric layer and the negatively charged redox probe. It was also likely that the PVC backbone of the polymer film acted like an insulating layer, thus reducing the electrical transfer across the Au surface. The subsequent activation of the carboxyl group produced a neutral ester intermediate. This newly formed neutral surface acted similarly to the previously mentioned neutral carboxylic functions: the absence of electrostatic interactions hindered the electron transfer process mediated by the negatively charged redox probe. The next stage was protein binding that also hindered the electrical transfer, reflected here by the increasing impedance values of the EIS spectra. Although Myo is positively charged under the $\mathrm{pH}$ condition of the redox probe solution (its isoelectric point is $\sim 7$ ), its size and packing over the surface must have contributed to this observation. This stage was followed by the polymerization reaction, producing again an additional barrier for the redox probe access to the gold SPE modified electrode. This resulted in an extra increase in the electron transfer resistance, reflected by further substantial increase in $R_{\mathrm{ct}}$. This subsequent increase in charge transfer resistant is consistent with the several modification steps imposed to the gold SPE surface.

\subsubsection{Cyclic voltammetry}

CV assays are not as sensitive as EIS but may serve as an additional confirmation of the chemical modification introduced on a gold surface. Overall, the results obtained supported the previous electrochemical studies (Fig. 3B). The application of PVC-COOH on gold resulted in a more irreversible electron transfer process due to the small current intensity and the high peak-to-peak potential separation of a typical iron redox probe over a clean Au surface. All the subsequent immobilization steps on the PVC-COOH film decreased or annulled the anodic/cathodic peaks of the redox probe and promoted further increase in peak-to-peak separation (when they existed), reducing the overall area of the voltammograms and accounting for the increased charge-transfer resistance on the gold surface. In the voltammograms where the cathodic and anodic peaks or the redox probe is not presented, the reaction of the redox probe was of irreversible character.

\subsection{Analytical features under electrochemical readings}

Nyquist plots and the corresponding calibration curves obtained from MIP/Au-SPE devices with different concentrations of Myo are shown in Fig. 4. The EIS assays were conducted in HEPES buffer, $\mathrm{pH}$ 5 , with $5.0 \mathrm{~mol} \mathrm{dm}^{-3}\left[\mathrm{Fe}(\mathrm{CN})_{6}\right]^{4-} /\left[\mathrm{Fe}(\mathrm{CN})_{6}\right]^{3-}$, at a standard potential of $0.225 \mathrm{~V}$, with a number of frequencies equal to 50 and an amplitude of $0.01 \mathrm{~V}$. The frequency range was $0.1-100 \mathrm{KHz}$.

The electron transference resistance $R_{\mathrm{ct}}$ controlled the electron transfer kinetics of the redox probe at the electrode interface, which was relative to the concentration of Myo. The diameter of the semicircle increased with the increasing of Myo concentration, meaning that Myo was binding to the imprinted material on the gold SPE/PVC-COOH surface. The results showed a linear 


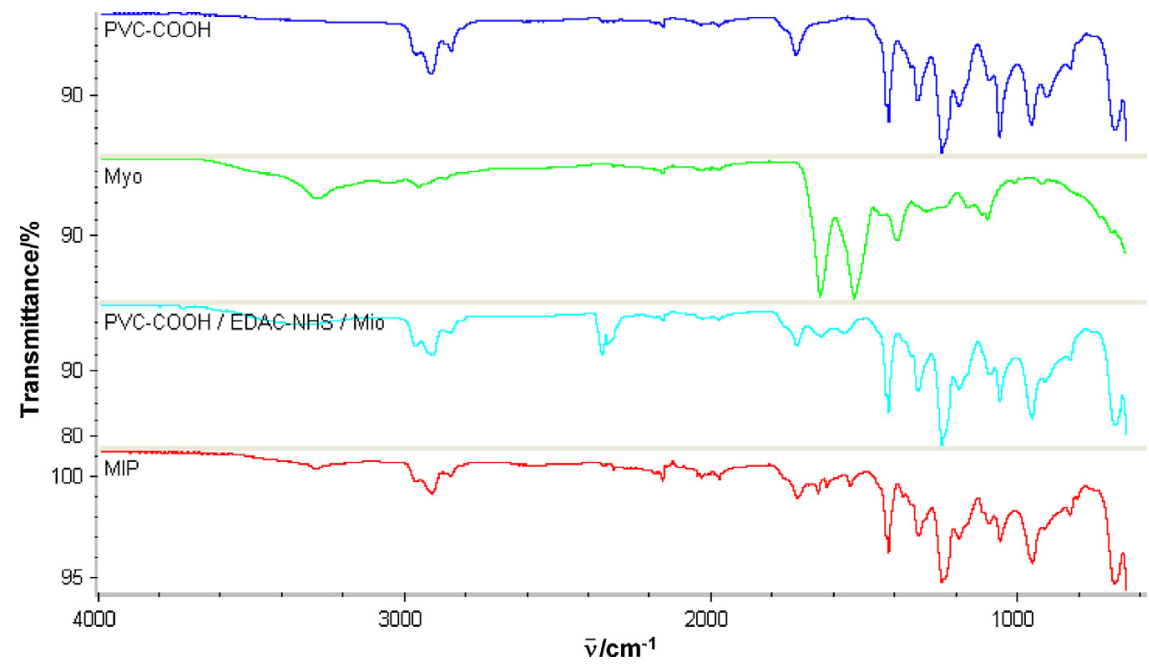

Fig. 2. FTIR analysis. (i) PVC-COOH; (ii) myoglobin; (iii) protein attach; (iv) MIP.
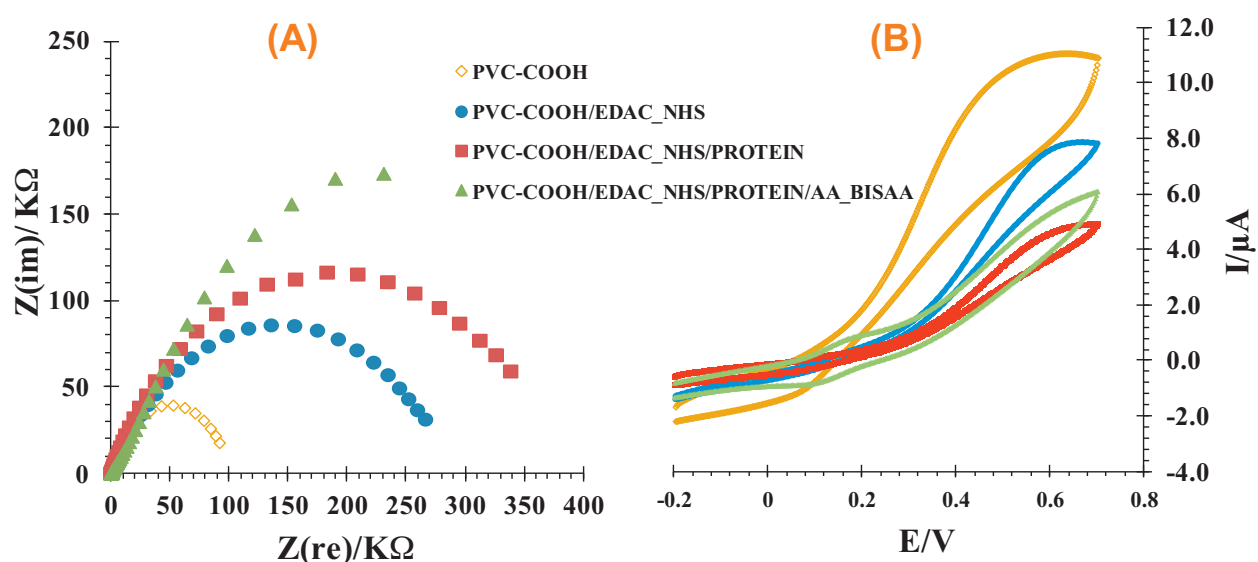

Fig. 3. (A) Nyquist plot of sequential immobilization steps on screen printed electrodes/PVC- $\mathrm{COOH}$ towards functional molecular imprinting sensor in $5.0 \mathrm{mM}[\mathrm{Fe}(\mathrm{CN}) 6]^{3-}$ and $5.0 \mathrm{mM}[\mathrm{Fe}(\mathrm{CN}) 6]^{4-}$ in HEPES buffer $\mathrm{pH} 5$ and frequency range was $0.1-100 \mathrm{KHz}$. (B) Cyclic voltammetry of sequential immobilization steps onto screen printed electrodes towards functional molecular imprinting sensor in $5.0 \mathrm{mM}[\mathrm{Fe}(\mathrm{CN}) 6]^{3-}$ and $5.0 \mathrm{mM}[\mathrm{Fe}(\mathrm{CN}) 6]^{4-}$ in HEPES buffer pH 5.

behaviour resistance versus Myo concentration, of positive slope $6.50 \pm 1.48 \mathrm{k} \Omega \mathrm{mL}_{\mu \mathrm{g}}{ }^{-1}$. This linear response was observed from 0.852 to $4.26 \mu \mathrm{g} \mathrm{mL}^{-1}$. The limit of detection was $2.25 \mu \mathrm{g} \mathrm{mL}^{-1}$ (Fig. 4).
As an alternative electrochemical approach to EIS, SWV was chosen this time instead of CV. SWV is much more sensitive than $\mathrm{CV}$, enabling the detection of much lower concentrations. These assays were conducted in the same solution as that in EIS
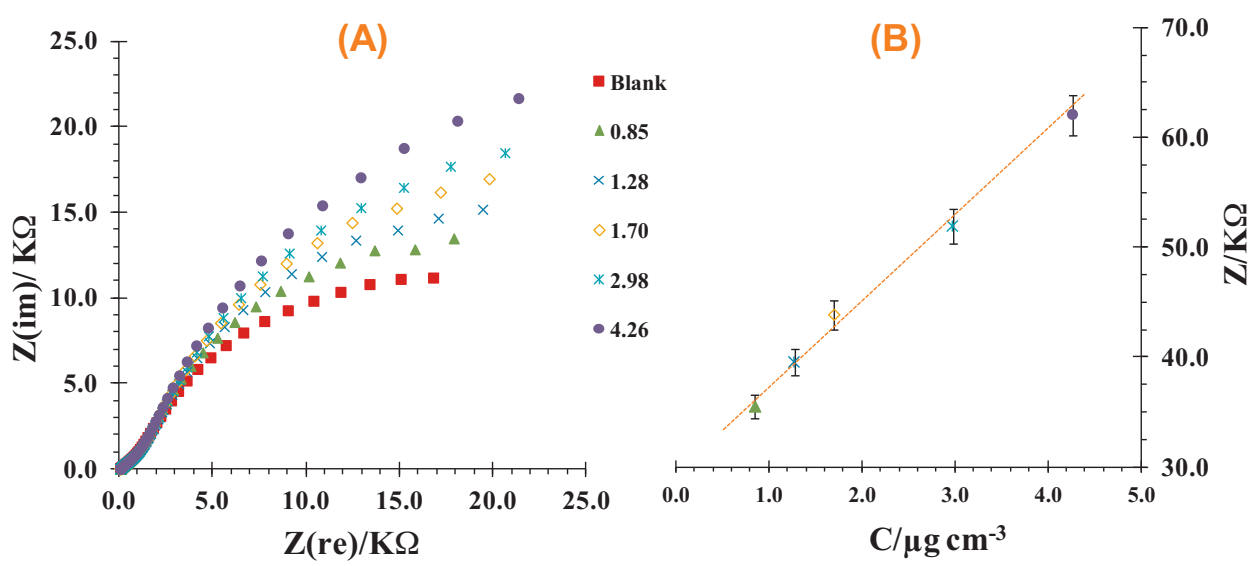

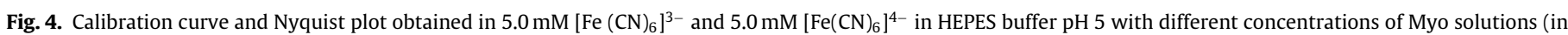
$\mu \mathrm{g} \mathrm{mL}{ }^{-1}$ ). 


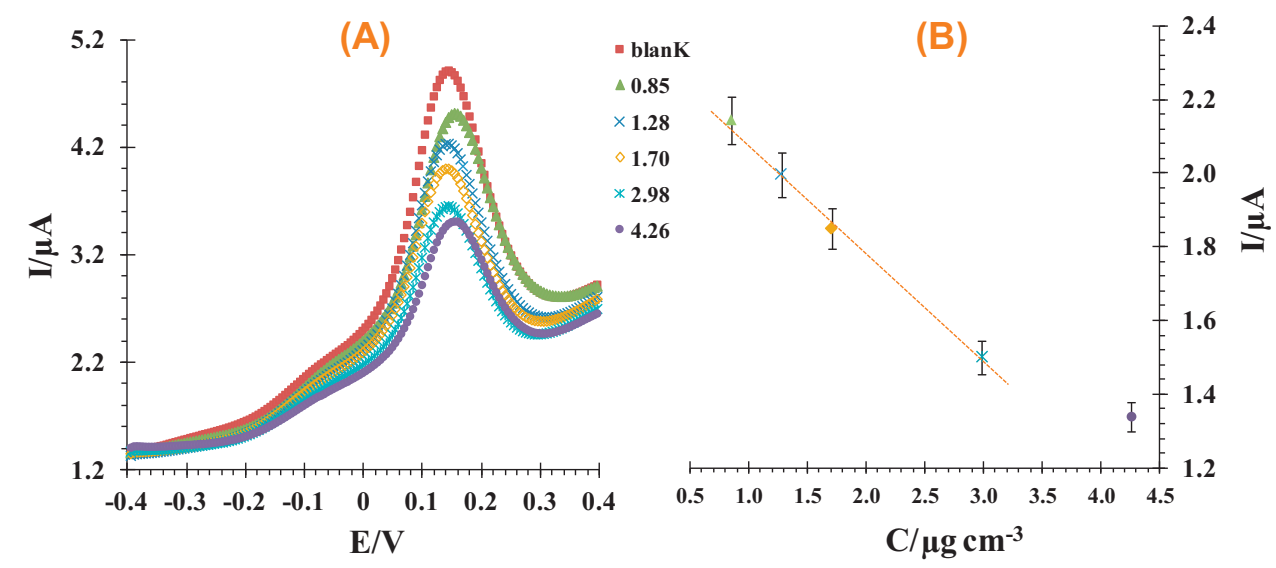

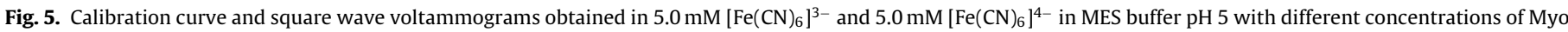
solutions (in $\mu \mathrm{g} \mathrm{mL}^{-1}$ ).

studies. Readings were carried out with amplitude of $0.15 \mathrm{~V}$ and scan rate of $30 \mathrm{mV} \mathrm{s}^{-1}$. The maximum peak of the blank was located at $0.139 \mathrm{~V}$, and corresponded to the oxidation potential of $\mathrm{Fe}(\mathrm{II})$. This peak shifted slightly to higher potentials as the concentration of Myo increased. This was consistent with the existence of a more difficult electrical transfer through probe when an increased concentration of Myo is present. Results showed linear slope $-0.28 \pm 0.038 \mu \mathrm{A} \mu \mathrm{g} \mathrm{mL}^{-1}$ decrease proportional to Myo concentration between 1.1 and $2.98 \mu \mathrm{g} \mathrm{mL}^{-1}$ (Fig. 5). In all measurements the repeatability was always less than $5 \%$. The biosensor is stable during 4 weeks and is reusable after with 3 consecutive calibrations curves, after rinsed with buffer several times along $30 \mathrm{~min}$.

For comparison purposes, a non-imprinted polymer material (NIP) based device was also tested. The calibration curves obtained in SWV showed linear slopes of $-0.177 \mu \mathrm{AmL} \mu \mathrm{g}^{-1}$ between 1.70 and $2.98 \mu \mathrm{g} \mathrm{mL}^{-1}$ Myo. EIS calibration curve showed linear slopes of $1.39 \mathrm{k} \Omega \mathrm{mL}^{-1}$ and linear behaviour down to

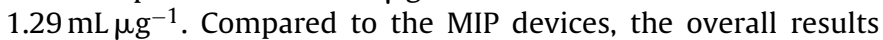
demonstrate the importance of including imprinted sites over the material in order to enhance the sensitivity of the determination. Overall, the NIP-device demonstrated lower sensitivity than the MIP one, revealing that the non-specific interaction between the polymer and template did not control the electrochemical response.

\subsection{Selectivity}

The interfering species tested were proteins that coexist with Myo in serum and their concentrations were selected according to their relative levels in biological fluids [40-43]. Cardiac biomarkers such as TnT and CKMB and a protein present in a biological fluids BSA were selected. A competitive assay was used to test their interference in the response of the sensor to a Myo level lying within the linear response range. A concentration of Myo equal to $4.0 \mu \mathrm{g} \mathrm{mL}^{-1}$ was selected for this purpose. This test was carried out along time, in order to reach the equilibrium between the binding sites of the sensory surface and the competition between Myo and interfering species for these binding sites. Each assay was conducted in a different Au-SPE/MIP sensor, avoiding a cross contamination from adsorbed Myo or interfering compound. The time and \% error found for each interfering species were, respectively, $5 \mathrm{~min}$ and $7 \%$ for TnT, $15 \mathrm{~min}$ and $11 \%$ for BSA and $15 \mathrm{~min}$ and $2 \%$ for urea, respectively. In all measurements the repeatability was always less than $5 \%$.

\subsection{Sensor response to synthetic serum samples}

Myo were determined in spiked diluted (1:10) synthetic serum samples and SWV measurements were performed. The sensor exhibited linear behaviour in range from 1.16 to $3.86 \mu \mathrm{g} \mathrm{mL}^{-1}$ $(Y=3.345-0.1372 X)$. The response time of the sensor was obtained in $<120$ s. In all measurements the repeatability was always less than $5 \%$.

\section{Conclusions}

A new sensory MIP material was presented and allowed the preparations of a disposal biomedical device for Myo screening. The use of a polymer film to assemble the MIP allowed the use of this concept to any other conductive material of any other commercial size/configuration SPE. The biosensor was based on electrochemical transduction: EIS and SWV offered simplicity in designing, low response time, good precision, high accuracy, and low limit of detection.

Compared to other biosensors made with natural antibodies, the MIP/Au-SPE showed similar analytical features especially concerning the ability to show linear ranges within the biological levels of Myo and good selectivity against other concomitant proteins. Furthermore, MIP/Au-SPE showed excellent properties in terms of robustness, reusability, response time and stability and these characteristics were incomparable with the natural sensing materials.

Overall, this method is considered simple, of low cost, and inexpensive and a suitable alternative for fast screening Myo in point-of-care. The major critical step of this work comes from the PVC membrane. The thickness cannot be controlled and other approach could be explored.

\section{Acknowledgement}

One of the authors (FTCM) gratefully acknowledges Fundação para a Ciência e Tecnologia for the financial support (PhD grant reference SFRH/BD/66735/2009).

\section{References}

[1] A.L. Hillberg, M. Tabrizian, Biomolecule imprinting: developments in mimicking dynamic natural recognition systems, IRBM 29 (2008) 89.

[2] B. Leca-Bouvier, L.J. Blum, Biosensors for protein detection: a review, Anal. Lett. 38 (2005) 1491.

[3] M.d. Vestergaard, K. Kerman, E. Tamiya, An overview of label-free electrochemical protein sensors, Sensors 7 (2007) 3442 
[4] M. Tudorache, C. Bala, Biosensors based on screen-printing technology, and their applications in environmental and food analysis, Anal. Bioanal. Chem. 388 (2007) 565

[5] J.P. Chambers, B.P. Arulanandam, L.L. Matta, A. Weis, J.J. Valdes, Biosensor recognition elements, Curr. Issues Mol. Biol. 10 (2008) 1.

[6] F.T.C. Moreira, R.A.F. Dutra, J.P.C. Noronha, M.G.F. Sales, Myoglobin-biomimetic electroactive materials made by surface molecular imprinting on silica beads and their use as ionophores in polymeric membranes for potentiometric transduction, Biosens. Bioelectron. 26 (2011) 4760.

[7] H.Y. Lin, C.Y. Hsu, J.L. Thomas, S.E. Wang, H.C. Chen, T.C. Chou, The microcontact imprinting of proteins: the effect of cross-linking monomers for lysozyme, ribonuclease A and myoglobin, Biosens. Bioelectron. 22 (2006) 534.

[8] E.G. Matveeva, Z. Gryczynski, J.R. Lakowicz, Myoglobin immunoassay based on metal particle-enhanced fluorescence, J. Immunol. Methods 302 (2005) 26.

[9] E.V. Suprun, A.L. Shilovskaya, A.V. Lisitsa, T.V. Bulko, V.V. Shumyantseva, A.I. Archakov, Electrochemical immunosensor based on metal nanoparticles for cardiac myoglobin detection in human blood plasma, Electroanalysis 23 (2011) 1051.

[10] F. Darain, P. Yager, K.L. Gan, S.C. Tjin, On-chip detection of myoglobin based on fluorescence, Biosens. Bioelectron. 24 (2009) 1744

[11] L. Piras, S. Reho, Colloidal gold based electrochemical immunoassays for the diagnosis of acute myocardial infarction, Sens. Actuators B: Chem. 111 (2005) 450.

[12] K. Haupt, K. Mosbach, Plastic antibodies: developments and applications, Trends Biotechnol. 16 (1998) 468.

[13] E. Yildirim, E. Turan, T. Caykara, Construction of myoglobin imprinted polymer films by grafting from silicon surface, J. Mater. Chem. 22 (2012) 636.

[14] K. Sefah, J.A. Phillips, X. Xiong, L. Meng, D. Van Simaeys, H. Chen, J. Martin, W. Tan, Nucleic acid aptamers for biosensors and bio-analytical applications, Analyst 134 (2009) 1765.

[15] F. Puoci, G. Cirillo, M. Curcio, O.I. Parisi, F. Iemma, N. Picci, Molecularly imprinted polymers in drug delivery: state of art and future perspectives, Expert Opin. Drug Deliv. 8 (2011) 1379.

[16] D. Kriz, O. Ramstrom, K. Mosbach, Molecular imprinting - new possibilities for sensor technology, Anal. Chem. 69 (1997) A345.

[17] V.M. Mirsky, T. Hirsch, S.A. Piletsky, O.S. Wolfbeis, A spreader-bar approach to molecular architecture: formation of stable artificial chemoreceptors, Angew. Chem. Int. Ed. 38 (1999) 1108

[18] M.J. Stone, M.R. Waterman, D. Harimoto, G. Murray, N. Willson, M.R. Platt, G. Blomqvist, J.T. Willerson, Serum myoglobin level as diagnostic test in patients with acute myocardial-infarction, Br. Heart J. 39 (1977) 375.

[19] E. Suprun, T. Bulko, A. Lisitsa, O. Gnedenko, A. Ivanov, V. Shumyantseva, A. Archakov, Electrochemical nanobiosensor for express diagnosis of acute myocardial infarction in undiluted plasma, Biosens. Bioelecton. 25 (2010) 1694.

[20] T.G. Donald, M.J. Cloonan, C. Neale, D.E.L. Wilcken, Excretion of myoglobin in urine after acute myocardial-infarction, Br. Heart J. 39 (1977) 29.

[21] M.J. Cloonan, G.A. Bishop, P.D. Wiltonsmith, I.W. Carter, R.M. Allan, D.E.L. Wilcken, Enzyme-immunoassay for myoglobin in human-serum and urine method development, normal values and application to acute myocardialinfarction, Pathology 11 (1979) 689.

[22] Y. Wang, Y. Zhou, J. Sokolov, B. Rigas, K. Levon, M. Rafailovich, A potentiometric protein sensor built with surface molecular imprinting method, Biosens. Bioelectron. 24 (2008) 162.

[23] P.-C. Liao, Y.-C. Tyan, C.-Y. Wang, J.-F. Hsu, T.-C. Chou, H.-Y. Lin, Assessing the binding selectivity of molecularly imprinted polymer artificial antibodies by mass spectrometry-based profiling system, J. Biomed. Mater. Res. Part A 91A (2009) 597.

[24] X.-Y.Zhao, F. Qu, M. Dong, F. Chen, A.-Q. Luo, J.-H. Zhang, Separation of proteins by aqueous two-phase extraction system combined with liquid chromatography, Chin. J. Anal. Chem. 40 (2012) 38.
[25] S. Modi, V.P. Shedbalkar, D.V. Behere, Spectrophotometric measurements on verdo-myoglobin - relevance to the oxidation of ferri-myoglobin by chlorite ion, Indian J. Biochem. 26 (1989) 84.

[26] C.F. Harrington, S. Elahi, S.A. Merson, P. Ponnampalavanar, A method for the quantitative analysis of iron speciation in meat by using a combination of spectrophotometric methods and high-performance liquid chromatography coupled to sector field inductively coupled plasma mass spectrometry, Anal. Chem. 73 (2001) 4422.

[27] B.M. Mayr, O. Kohlbacher, K. Reinert, M. Sturm, C. Gropl, E. Lange, C. Klein, C.G. Huber, Absolute myoglobin quantitation in serum by combining two-dimensional liquid chromatography-electrospray ionization mass spectrometry and novel data analysis algorithms, J. Prot. Res. 5 (2006) 414.

[28] S. Pakapongpan, R. Palangsuntikul, W. Surareungchai, Electrochemical sensors for hemoglobin and myoglobin detection based on methylene bluemultiwalled carbon nanotubes nanohybrid-modified glassy carbon electrode, Electrochim. Acta 56 (2011) 6831.

[29] S.K. Mishra, D. Kumar, A.M. Biradar, Rajesh, Electrochemical impedance spectroscopy characterization of mercaptopropionic acid capped ZnS nanocrystal based bioelectrode for the detection of the cardiac biomarker-myoglobin, Bioelectrochemistry 88 (2012) 118.

[30] M. Billah, H.C.W. Hays, P.A. Millner, Development of a myoglobin impedimetric immunosensor based on mixed self-assembled monolayer onto gold, Microchim. Acta 160 (2008) 447.

[31] T.M. O’Regan, L.J. O'Riordan, M. Pravda, C.K. O’Sullivan, G.G. Guilbault, Direct detection of myoglobin in whole blood using a disposable amperometric immunosensor, Anal. Chim. Acta 460 (2002) 141.

[32] Rajesh, V. Sharma, V.K. Tanwar, S.K. Mishra, A.M. Biradar, Electrochemical impedance immunosensor for the detection of cardiac biomarker myoglobin (Mb) in aqueous solution, Thin Solid Films 519 (2010) 1167.

[33] V. Shumyantseva, E. Suprun, T. Bulko, A. Archakov, Electrochemical methods for the investigation of bioaffinity interactions based on gold nanoparticles modified sensors, Electroanalysis 21 (2009) 5.

[34] D. Tong, C. Hetenyi, Z. Bikadi, J.P. Gao, S. Hjerten, Some studies of the chromatographic properties of gels ('artificial antibodies/receptors') for selective adsorption of proteins, Chromatographia 54 (2001) 7.

[35] S. Wu, W. Tan, H. Xu, Protein molecularly imprinted polyacrylamide membrane: for hemoglobin sensing, Analyst 135 (2010) 2523.

[36] T.Y. Guo, Y.Q. Xia, G.J. Hao, M.D. Song, B.H. Zhang, Adsorptive separation of hemoglobin by molecularly imprinted chitosan beads, Biomaterials 25 (2004) 5905.

[37] M. Zhang, J. Huang, P. Yu, X. Chen, Preparation and characteristics of protein molecularly imprinted membranes on the surface of multiwalled carbon nanotubes, Talanta 81 (2010) 162

[38] X.S. Pang, G.X. Cheng, S.L. Lu, E.J. Tang, Synthesis of polyacrylamide gel beads with electrostatic functional groups for the molecular imprinting of bovine serum albumin, Anal. Bioanal. Chem. 384 (2006) 225.

[39] M.A. Panagopoulou, D.V. Stergiou, I.G. Roussis, M.I. Prodromidis, Impedimetric biosensor for the assessment of the clotting activity of rennet, Anal. Chem. 82 (2010) 8629.

[40] G. Landesberg, V. Shatz, I. Akopnik, Y.G. Wolf, M. Mayer, Y. Berlatzky, C. Weissman, M. Mosseri, Association of cardiac troponin, CK-MB, and postoperative myocardial ischemia with long-term survival after major vascular surgery, J. Am. Coll. Cardiol. 42 (2003) 1547.

[41] M.D. Kertai, E. Boersma, J. Klein, H. van Urk, J.J. Bax, D. Poldermans, Long-term prognostic value of asymptomatic cardiac troponin $\mathrm{T}$ elevations in patients after major vascular surgery, Eur. J. Vasc. Endovasc. 28 (2004) 59.

[42] C.J. McCann, B.M. Glover, I.B.A. Menown, M.J. Moore, J. McEneny, C.G. Owens, B. Smith, P.C. Sharpe, I.S. Young, J.A. Adgey, Novel biomarkers in early diagnosis of acute myocardial infarction compared with cardiac troponin T, Eur. Heart J. 29 (2008) 2843.

[43] K. Lewandrowski, A. Chen, J. Januzzi, Cardiac markers for myocardial infarction: a brief review, Am. J. Clin. Pathol. 118 (2002) S93. 